\title{
Expanded syringe exchange programs and reduced HIV infection among new injection drug users in Tallinn, Estonia
}

Anneli Uusküla ${ }^{1 *}$, Don C Des Jarlais ${ }^{2 \dagger}$, Mart Kals $^{1 \dagger}$, Kristi Rüütel ${ }^{3 \dagger}$, Katri Abel-Ollo ${ }^{4 \dagger}$, Ave Talu ${ }^{4 \dagger}$ and Igor Sobolev ${ }^{5+}$

\begin{abstract}
Background: Estonia has experienced an HIV epidemic among intravenous drug users (IDUs) with the highest per capita HIV prevalence in Eastern Europe. We assessed the effects of expanded syringe exchange programs (SEP) in the capital city, Tallinn, which has an estimated 10,000 IDUs.

Methods: SEP implementation was monitored with data from the Estonian National Institute for Health Development. Respondent driven sampling (RDS) interview surveys with HIV testing were conducted in Tallinn in 2005, 2007 and 2009 (involving 350, 350 and 327 IDUs respectively). HIV incidence among new injectors (those injecting for $<=3$ years) was estimated by assuming (1) new injectors were HIV seronegative when they began injecting, and (2) HIV infection occurred at the midpoint between first injection and time of interview.
\end{abstract}

Results: SEP increased from 230,000 syringes exchanged in 2005 to 440,000 in 2007 and 770,000 in 2009. In all three surveys, IDUs were predominantly male (80\%), ethnic Russians (>80\%), and young adults (mean ages 24 to 27 years). The proportion of new injectors decreased significantly over the years (from 21\% in 2005 to $12 \%$ in 2009, $p=0.005)$. HIV prevalence among all respondents stabilized at slightly over 50\% (54\% in $2005,55 \%$ in $2007,51 \%$ in 2009), and decreased among new injectors (34\% in 2005, $16 \%$ in 2009, $p=0.046$ ). Estimated HIV incidence among new injectors decreased significantly from 18/100 person-years in 2005 and 21/100 person-years in 2007 to 9/100 person-years in 2009 ( $p=0.026)$.

Conclusions: In Estonia, a transitional country, a decrease in the HIV prevalence among new injectors and in the numbers of people initiating injection drug use coincided with implementation of large-scale SEPs. Further reductions in HIV transmission among IDUs are still required. Provision of 70 or more syringes per IDU per year may be needed before significant reductions in HIV incidence occur.

\section{Background}

The estimated number of adults and children living with HIV in Eastern Europe and Central Asia rose to 1.5 million in 2008, a 66\% increase from 0.9 million in 2001. Three countries in the region (Estonia, Russian Federation and Ukraine) have adult (15-49) HIV prevalence that exceeds $1 \%$ [1]. Injecting drug use remains the primary mode of HIV transmission in the region [1,2]. Although coverage with HIV prevention, treatment and care services (syringe exchange programs (SEPs), opioid substitution therapy

\footnotetext{
* Correspondence: anneli.uuskula@ut.ee

+ Contributed equally

${ }^{1}$ Department of Public health, University of Tartu, Ravila street, 50411 Tartu, Estonia

Full list of author information is available at the end of the article
}

(OST) and antiretroviral therapy (ART)) for injecting drug users (IDUs) remains low in the region, scattered progress has been reported in expanding SEP and OST programs [3]. Availability of SEP, OST programs and ART and government policies supporting these programs varies widely across the regions. It is estimated that in Eastern Europe an average of 9 needles/syringes are distributed by injection drug user (IDU) per year (ranging from 4 in Russia to 151 in Czech Republic), 1\% of IDUs receive OST (ranging from $1 \%$ in Georgia and Belarus to $20 \%$ in Hungary), and $1 \%$ of HIV infected IDUs receive ART (ranging from $<1 \%$ in Russia to $81 \%$ in Czech Republic) [3].

There is considerable evidence that HIV-prevention programs for IDUs, particularly combined programming, in which multiple programs are provided, can be effective 
in reducing injection-related HIV transmission $[4,5]$. In many areas in industrialized countries, it has been possible to keep prevalence low indefinitely, literally preventing HIV epidemics among IDUs [6-9]. It is also possible to "reverse" large-scale HIV epidemics among IDUs (i.e. to greatly reduce both HIV incidence and prevalence) with large scale prevention efforts applied over long periods [10-13]. However, there has been relatively little research, other than pilot studies, on the effects of syringe exchange in developing/transitional countries. It is therefore uncertain whether the interventions used in developed countries will have the same degree of effectiveness in transitional countries where these interventions might operate in a hostile policy environment.

Data on new injectors (i.e. people who have started to inject drugs recently) can provide critical insights into the dynamics of an ongoing HIV epidemic among IDUs. First, the proportion of new injectors provides information about the growth of the population at risk of HIV. Second, in epidemics that are driven by injecting drug use with little sexual transmission, all or almost all IDUs will be HIV seronegative when they begin injecting $[14,15]$. In these situations HIV prevalence among new injectors can be used to estimate HIV incidence. Third, new injectors are often the most difficult subgroup to reach with HIV prevention services - possibly because they do not identify themselves as drug injectors [16] so that information on whether new injectors are using HIV prevention services can be a good measure of the reach of prevention services.

In this report, we examine trends in new injectors in the IDU population in Tallinn, Estonia from 2005 to 2009 in relation to the expansion of harm reduction services during the same time period.

Estonia has experienced a concentrated HIV epidemic among IDUs, with the highest per capita HIV prevalence in Eastern Europe. There are an estimated 10,000 IDUs (approximately 70\% of IDUs in the country) in Tallinn, the capital and largest city [17]. Studies in Estonia have shown a high prevalence of HIV (40-90\%) $[18,19]$, and estimated the incidence of HIV in the IDU population $>20 / 100$ person years at risk [20]. Based on data from surveys conducted among IDUs in Tallinn [18,19,21], a shift in use from heroin and home-made opiates to fentanyl analogues and amphetamine has occurred during the current decade.

Estonia's capacity to manage its response to HIV and AIDS has increased greatly over the past five years, particularly through funding from the Global Fund to fight HIV/AIDS, tuberculosis, and malaria [22]. Global Fund support was also instrumental in building capacity for the governmental and nongovernmental sectors to interact constructively with each other. This included establishing systems for channeling funds through government to
NGOs and mechanisms for dialogue [23]. Amongst other activities, reducing the risk of harm faced by IDUs by scaling-up syringe exchange programs and drug treatment were implemented. The National Institute for Health Development (NIHD) is an agency of the Ministry of Social Affairs and is responsible for implementing and monitoring the majority of the state prevention programs (including those targeting HIV/AIDS and drug use). Detailed descriptions of the HIV epidemic in Estonia and response to the epidemic can be found elsewhere [24]. SEPs were initiated in Estonia in 1997, in Tallinn. By 2009 in Tallinn, 3 organizations were providing SEP through 3 stationary centers (and 7 outreach locations) with 63,333 registered visits ( 1 center, 2341 visits in 2003; 2 centers, 30,863 visits in 2005) (Table 1) [25]. Methadone detoxification has been available in Estonia since 1998, but opioid substitution maintenance treatment with methadone was officially introduced in 2001 [24]. By the end of 2009 in Tallinn 3 institutions ( 3 centers) were providing opioid substitution treatment (Table 1) [25].

In Estonia, during the past 10 years the number of patients on ART has increased from 27 in 2000 to 1751 at the end of 2010 [personal communication, Mr. Mihkel Rääk, Ministry of Social Affairs, Estonia, 24.01.2011]. However, only $5-12 \%$ of HIV-infected IDUs have reported currently receiving ART [26].

\section{Methods}

Cross sectional studies in 2005, 2007 and 2009 were conducted to assess the prevalence of HIV and risk behavior among IDUs in Tallinn, Estonia. In each study, current IDUs were recruited for an interviewer-administered risk behavior survey covering demographics, drug use history, and HIV risk behavior. HIV counseling was provided and a blood sample was collected for HIV testing. Participants had to: be 18 years or older, be Russian or Estonian speakers, have injected drugs in the previous two months (one month in 2005), and be able to provide informed consent.

Respondent driven sampling (RDS) $[18,19]$ was used in all three surveys. Recruitment began with the non-random selection of 5 - 6 'seeds' representing diverse IDU types (by gender, ethnicity, main type of drug used, and HIV status). Eligible participants received coupons for recruiting up to three of their peers. Coupons were uniquely coded to link participants to their survey responses and biological specimens and for monitoring who recruited whom. Participants who completed the study received a primary incentive (a food coupon worth \$ 10) for participation in the study and a secondary incentive (a food coupon worth $\$ 5$ for each eligible person they recruited to the study). The RDS technique uses participants' social networks to access individuals who might not appear in public venues and might not be in contact with service providers. This 
Table 1 Volume of harm reduction services provided in 2003 to 2009 in Tallinn, Estonia

\begin{tabular}{lccccccc}
\hline Year & $\mathbf{2 0 0 3}$ & $\mathbf{2 0 0 4}$ & $\mathbf{2 0 0 5}$ & $\mathbf{2 0 0 6}$ & $\mathbf{2 0 0 7}$ & $\mathbf{2 0 0 8}$ & $\mathbf{2 0 0 9}$ \\
\hline No of syringes distributed & 18,010 & 129,093 & 230,409 & 443,961 & 600,021 & 734,954 & 774,782 \\
\hline No of condoms distributed throughout SEPs & 16,427 & 76,004 & 83,975 & 134,837 & 158,164 & 156,735 & 131,162 \\
\hline No of positions for methadone treatment & & 46 & 103 & 183 & 200 & 191 & 209 \\
\hline
\end{tabular}

technique has been proven to be effective for recruiting IDUs $[27,28]$. A face-to-face interviewer-administered structured questionnaire was used. In 2007 and 2009 the questionnaire was based on the WHO Drug Injecting Study Phase II survey (version 2b(rev.2)) [29], and in 2005, the questionnaire was adapted from several studies in resource-constrained and developed countries, including the Russian Federation [30,31]. Both instruments were originally developed to collect risk behavior data from IDUs, and therefore contained similar measures on key behavior characteristics (age, gender, age at injection initiation, injection frequency, main drug injected, receptive sharing within last 4 weeks, SEP utilization [ever, and in the last 4 weeks], number of sexual partners within last 12 months). The instruments were modified to obtain information on the illicit drugs known to be available in Tallinn.

Questions were selected that would elicit data on demographics, drug use history, HIV risk behavior, HIV testing, access and use of harm reduction services. A question on age at first injection was included, permitting calculation of the number of years the participant had been injecting. Interviews were held in confidence, in a room of the SEP. Recruitment was conducted and the survey administrated by a team of trained fieldworkers.

Blood was collected for HIV testing. In 2005 dried blood spot specimens were tested for HIV antibodies using GACELISA, reactive specimens were confirmed using an anti-HIV GACPAT immunoassay, with confirmatory testing conducted on discordant results using the HIV Blot 2.2 Western Blot assay (AbbotMurex) [32,33]. In 2007 and 2009, venous blood was tested with commercially available kits for HIV antibodies (Abbott IMx HIV-1/HIV-2 III Plus, Abbott Laboratories, Abbott Park, Illinois, USA).

Several studies comparing HIV antibody testing performance from serum (venous blood) and dried blood spots have documented excellent agreement of results between these different methods [34-36].

Data on the level of HIV prevention services provided were obtained from the Estonian National Institute for Health Development.

\section{Statistical analysis}

HIV incidence can be estimated from cross-sectional data using prevalence data [37] stratified by time at risk (years of injecting) and assuming that HIV prevalence differences between the years of IDU duration strata represent incident HIV infections [10,20]. The questionnaires included questions on current age and age at first drug injection. Subtraction of age at first injection from current age provided a measure of the number of years injecting.

We estimated HIV incidence among new injectors using the following assumptions: (1) all of them were HIV seronegative when they began injecting; (2) the HIV seropositives became infected at the midpoint between beginning to inject and the time of blood sample collection, and (3) no HIV seropositives were lost to AIDS or for other reasons among the new injectors. We limited our analysis to "new injectors" (defined as a person reporting his/her first injection as occurring within three years of the study interview). For calculating time since first injection, we assigned persons who had first injected at their current age to have been injecting for 6 months, persons who first injected in the previous year to have been injecting for 1 year, persons who had first injected two years prior to their current age to have been injecting for 2 years, and persons who had first injected three years prior to their current age to have been injecting for 3 years. The time at risk for HIV seronegative new injectors is the total time from first injection to the time of the interview. The estimated HIV incidence rate was the number of HIV seropositive new injectors divided by the sum of the time at risk for the HIV seropositive new injectors (half the total time from beginning to inject to the time of interview) and the time at risk for the HIV seronegative new injectors (total time from beginning to inject to time of interview).

Study participation in all three studies was anonymous. To control for potential duplication in the samples $(2005,2007,2009)$ a combination of biometric measures of each respondent (width of each wrist and length of each forearm from elbow to middle finger) and selected personal characteristics (sex, ethnicity, age) was used. Using this method, we identified one person who possibly participated in years 2005 and 2007. This person was retained for the analysis in both years, given the need for sufficiently large samples of new injectors, and that the HIV status, time at risk, use of syringe exchange, etc for that subject interviewed in 2005 would have reflected conditions in 2005, while if the same subject were interviewed in 2007, the subject's characteristics would primarily reflect conditions in 2006 in addition to reflecting conditions in 2007. 
Risk behaviors and characteristics of 'new injectors' were compared in 2005, 2007, and 2009. Pearson's $\chi^{2}$, $\chi^{2}$ test for trend and Fisher's exact tests were used for categorical variables. A multivariate analysis (controlling for age, sex, frequency of drug and SEP use) was used to test for trends in HIV prevalence [38].

RDS analysis Tool v. 5.0.1 was used to calculate homophily (the extent to which recruiters are likely to recruit individuals similar to themselves) to examine for possible recruitment bias [39].

Ethical approval was obtained from the Ethics Review Board of the University of Tartu, Estonia (in 2005 and 2009) and from the Tallinn Medical Research Committee (in 2007).

\section{Results}

Table 1 shows the harm reduction services provided to IDUs in Tallinn from 2003 through 2009. The number of methadone treatment positions ("slots") increased from 49 to 209. With an estimated 10,000 IDUs in the city, however, the latest number of methadone treatment positions is still quite low, with methadone treatment available for only approximately $2 \%$ of the IDU population. Since 2004 the number of syringes distributed through SEPs (both stationary and outreach) in Tallinn has increased more than 6 -fold. This corresponds to an estimated coverage of 70 or more syringes per IDU per year in $2008(73.5=734,954 / 10,000)$ and 2009 $(77.5=774,782 / 10,000)$.

We recruited 350 current IDUs in both 2005 and 2007 and 327 IDUs in 2009. In all three surveys, IDUs were predominantly male (80\%), ethnic Russians (>80\%), and young adults (mean ages 24 to 27 years) (full details from individual surveys are available from the first author). The proportion of new injectors (those injecting for less than three years) among the IDUs decreased from $21 \%$ in 2005 , to $16 \%$ in 2007, and $12 \%$ in 2009 ( $p<0.005$ by $\chi^{2}$ test). Estimates for homophily indexes for the type of IDU (new and old injectors) in all three samples were close to zero, suggesting a single underlying population for each round of recruitment and non selective recruitment between the two IDU groups (i.e. new and old injectors) [27].

HIV prevalence among all subjects stabilized at slightly over $50 \%$ ( $54 \%$ in $2005,55 \%$ in $2007,50 \%$ in 2009 ). There were statistically significant differences in HIV prevalence among new injectors, with the prevalence in 2009 less than half that in 2007 (15.8\% vs 34.2\%) (Table 2). There were, however, differences in demographic characteristics and drug use behaviors among new injectors across the surveys. We used multiple regression [38] to determine if the differences in HIV prevalence remained statistically significant after controlling for age, gender, injection frequency and SEP use. The differences in HIV prevalence among new injectors remained statistically significant (Chi squared $=8.31, \mathrm{p}=0.016$ ).

We also observed significant changes in the estimated HIV incidence among new injectors. In 2005 and 2007, the estimated incidences among new injectors were 20.9 per 100 person years (py), compared with $9.0 / 100$ py in 2009 (Table 2).

During the period of the three surveys, there was an increase in the age of IDUs both in terms of chronological age and age of starting injecting (Table 3). Reported injection risk behaviors (any receptive sharing in the past 4 weeks) did not change over the three surveys. However, the proportion of new injectors reporting having used SEP services increased steadily throughout the study period (from $70 \%$ in 2005 to $97 \%$ in 2009), as did the proportion of new injectors for whom an SEP was the current main source of syringes (from 44\% in 2005 to $76 \%$ in 2009). We did not see significant changes in reported numbers of sexual partners within the last 12 months or in condom use. There was a slight (but statistically not significant, $\mathrm{p}=0.08$ ) increase in the proportion of new IDUs who reported not always using condoms (37\% in 2005, 58\% in 2009).

\section{Discussion}

We have used a series of cross sectional studies conducted among IDUs over a period in which harm reduction services (mainly SEPs) were introduced and then expanded to examine the possible effects of such programs in an Eastern European country.

Several findings from our study are potentially important. The proportion of new injectors among IDUs across the surveys decreased; this suggests a decreasing rate of individuals becoming IDUs. Drug use patterns are not static, for example Estonia and several other Eastern European countries witnessed explosive IDU epidemics in the late 1990s. Limited data on the course of IDU epidemics after their emergence is available. In Russia, $47 \%$ of IDUs recruited in 2003 from Moscow, Volgograd and Barnaul [40] and 42\% of IDUs recruited from St Petersburg in 2005-2006 [41] were new injectors (reporting injecting for $<5$ years). In Russia, $47 \%$ of IDUs recruited in 2003 from Moscow, Volgograd and Barnaul [40] and 42\% of IDUs recruited from St Petersburg in 2005-2006 [41] reported injecting for $<5$ years. These findings are very similar to the $41 \%$ of IDUs recruited in Tallinn in our 2005 survey who reported injecting for $<5$ years. (In our 2005 survey $21 \%$ of subjects reported injecting for $<=3$ years, see Table 2.) In Estonia, the decrease in numbers of new injectors occurred at the same time as the increase in SEP services. This contradicts the idea that providing SEP will lead to an increase in people beginning to inject drugs. Our sampling methods (RDS) did not change over the three surveys and no substantial changes of drug 
Table 2 New injectors, HIV prevalence and estimated incidence among new injectors (persons injecting less than 3 years) among surveys of IDUs in Tallinn, Estonia in 2005, 2007 and 2009

\begin{tabular}{lcccccccc}
\hline & \multicolumn{3}{c}{ The proportion of new injectors * } & \multicolumn{3}{c}{ HIV prevalence ** } & \multicolumn{2}{c}{ HIV incidence per 100 PY *** } \\
\hline Year & New & All & $\%$ & HIV+ & $\%$ & $\mathbf{9 5 \%} \mathbf{C l}$ & $\mathbf{9 5 \% ~ C I}$ \\
\hline $\mathbf{2 0 0 5}$ & 73 & 350 & $20,9 \%$ & 25 & $34,2 \%$ & $22.2-50.6 \%$ & 20,9 & $13.5-30.8$ \\
\hline $\mathbf{2 0 0 7}$ & 57 & 350 & $16,3 \%$ & 22 & $38,6 \%$ & $24.2-58.4 \%$ & 26,5 & $16.6-40.1$ \\
\hline $\mathbf{2 0 0 9}$ & 38 & 327 & $11,6 \%$ & 6 & $15,8 \%$ & $5.8-34.4 \%$ & 9,0 & $3.3-19.6$ \\
\hline
\end{tabular}

* for changes of the period $p=0.005$ (Chi-squared Test); ${ }^{* *}$ for changes of the period $p=0.046$ (Fisher Exact test); ${ }^{* *}$ for changes of the period $p=0.026$ (Chi-squared Test)

Table 3 Socio-demographic and behavioural (risk) characteristics among new drug injectors in 2005, 2007, and 2009, in Tallinn, Estonia

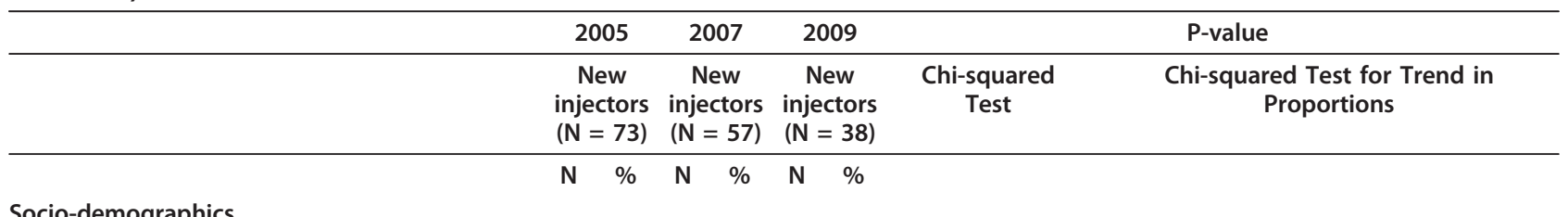

\section{Age (years)}

$<=20$

$>20$

Gender

Male

Female

\section{Ethnicity}

Russian+Russian speaking

Environmental factors

Ever in drug treatment

No

$\begin{array}{llllll}59 & 81 \% & 48 & 84 \% & 33 & 87 \%\end{array}$

Yes

Ever in prison

No

SEP use ever

No

SEP as the main source of syringes (last 4 weeks)
No
Yes

Injecting drug use

Age at IDU initiation (years)

$<=16$
$>16$ 
Table 3 Socio-demographic and behavioural (risk) characteristics among new drug injectors in 2005, 2007, and 2009, in Tallinn, Estonia (Continued)

Frequency of injection (last 4 weeks)

Less than daily

Daily $\begin{array}{llllll}57 & 78 \% & 30 & 53 \% & 27 & 71 \%\end{array}$

$\begin{array}{llllll}16 & 22 \% & 27 & 47 \% & 11 & 29 \%\end{array}$
0.189

Main drug injected (last 4 weeks)

Fentanyl

Amphetamine

$\begin{array}{llllll}35 & 48 \% & 33 & 58 \% & 23 & 61 \% \\ 34 & 47 \% & 23 & 40 \% & 12 & 32 \%\end{array}$

0.321

0.132

Receptive sharing (last 4 weeks)

No

Yes

$54 \quad 74 \% \quad 47 \quad 82 \% \quad 30 \quad 79 \%$

$\begin{array}{llllll}19 & 26 \% & 10 & 18 \% & 8 & 21 \%\end{array}$

0.505

0.435

Sexual behaviors

Number of sexual partners (last 12 months)

0-1

$1+$

$\begin{array}{llllll}32 & 44 \% & 37 & 65 \% & 15 & 39 \%\end{array}$

$\begin{array}{llllll}40 & 55 \% & 20 & 35 \% & 23 & 61 \%\end{array}$

0.022

0.984

Condom use (last 4 weeks)*

always

else

* Among those reporting vaginal or anal intercourses with in last 4 weeks

availability have occurred over the period under observation $[25,42]$. While the belief that SEP leads to more people beginning to inject drugs has generally been discredited [4,8], it is important to test this belief in middle income countries, where resistance to large-scale harm reduction remains strong.

We observed a significant decrease in the prevalence of HIV among new injectors from 34\% and 39\% in 2005 and 2007 to $16 \%$ in 2009 . We also observed a decrease in the estimated HIV incidence among new injectors from up to $27 / 100$ py in 2005 and 2007 to $9.0 / 100$ py in 2009 . The estimated incidence among new injectors showed a nonsignificant rise in 2007 (and a decline by 2009) coinciding with the rise and decline in the proportion of new injectors reporting daily injecting. While the level of HIV infection among new injectors in Estonia is still clearly unacceptably high, the change from the preceding years is substantial. Acknowledging that, in Estonia, active treatment for addiction (i.e. opioid substitution treatment) coverage and ART coverage among HIV infected IDUs [26] were implemented at a suboptimal level [43] during this period, preventing any meaningful public-health level effect, it is reasonable to attribute the decrease in HIV infection among new injectors to the greatly increased access to clean syringes/SEPs.

\section{Limitations}

The cross-sectional design of the study sets well-known limits for causal inference. However, repeated cross- sectional studies may be considered to constitute a pseudolongitudinal study, given that the IDUs recruited in the studies were sampled from the IDU source population using the same methodology. We used a non-probability sample that may have implications for the representativeness of the study results. However, RDS was used for recruitment because it is a sampling technique known to overcome some of the limitations of convenience sampling $[27,28]$. Other potential sources of bias associated with the sensitive and illegal behaviors under investigation are socially desirable responses and recall bias. However, we suggest that this would be expected to influence study participants in a similar way in different years. In addition, for HIV incidence estimations we made assumptions that might not hold. There is a possible loss of HIV seropositives from the active new injector population, due to ceasing to inject (perhaps because of methadone use), and to death/disability from AIDS. To minimize those effects we estimated the incidence only among new injectors, those who have injected for only a short period (3 years), and who would have been very unlikely to have developed AIDS and, given the limited availability of methadone treatment in Tallinn, they would also have been very unlikely to have received methadone treatment. It is of importance to note that we do not have data on the potential changes in IDU prevalence in Tallinn. However there are no declines in the numbers of criminal offences that can be related to the drug use or in the numbers of drug use related deaths in the recent years (2006-2009) [42]. 
It is also possible that the questions we used to measure injecting risk behavior did not capture important changes in injecting risk. For example, it is possible that IDUs in Tallinn reduced the frequency with which they shared injecting equipment (which would not be captured by the "any sharing" questions), or that they reduced the numbers of persons with whom they shared, or that some form of serosorting occurred, in which HIV seronegatives were more likely to share with other seronegatives and HIV seropositives were more likely to share with other seropositives. The numbers of syringes provided to IDUs may be a better measure of transmission probability than questions on "any sharing" during a short time period.

IDUs in Tallinn also obtain sterile injection equipment from pharmacies [28] and we were not able to determine the numbers of syringes obtained from pharmacies over the 2005 to 2009 time period. Despite some imprecision in determining the numbers of sterle needles and syringes obtained by IDUs in Tallinn over the time period covered by the surveys, it is clear from the data in Table 1 that there was a very substantial incorease in the provision of sterile injecting equipment. The coverage of 70 syringes per IDU per year reached by 2009 corresponds to the low coverage indicator set by the WHO, UNODC, UNAIDS for universal access to HIV prevention, treatment and care for injecting drug users [43], based on studies in the UK and Belarus [44] and the USA [45].

\section{Conclusions}

Allocating resources for the prevention of HIV infection among IDUs is a challenging task. A large-scale SEP appears to have been quite effective in Estonia (a transitional country), although further reductions in HIV transmission among IDUs are still required. Coverage of 70 or more syringes per IDU per year may be needed before significant reductions in HIV incidence occur.

\footnotetext{
Acknowledgements

The results of the 2005 study were published separately. We are grateful to Tim Rhodes, Lucy Platt, Natalja Bobrova and colleagues from the London School of Hygiene and Tropical Medicine for their contribution to the 2005 data collection, analysis and publications.

We thank Aire Trummal from the Department of Surveillance and Evaluation of the National Institutes for Health (Estonia) for the data on the level of HIV prevention services provided in Tallinn, Estonia.

We are also grateful to the participants for their co-operation and to the study team at the NGO Convictus, Tallinn, Estonia.

Funding

The study was supported by the Civilian Research Development Foundation (grants ESX0-2722-TA-06 and ESBI-7002-TR-08); by EU commission funded project "Expanding Network for Coordinated and Comprehensive Actions on HIV/AIDS Prevention among IDUs and Bridging Populations" No 2005305; by The Global Fund to Fight AIDS, Tuberculosis and Malaria project "Scaling up the response to HIV in Estonia"; grant SF0180060s09 from the Estonian Ministry of Education and Research; and grants R01 035174 and R01 Al083035 from the US National Institutes of Health.
}

\section{Author details}

'Department of Public health, University of Tartu, Ravila street, 50411 Tartu, Estonia. ${ }^{2}$ Edmond de Rothschild Chemical Dependency Institute, Beth Israel Medical Center, West 57th Street, New York, NY 10019, USA. ${ }^{3}$ Department of Infectious Diseases and Drug Prevention, National Institute for Health Development, Hiiu street, 11619 Tallinn, Estonia. ${ }^{4}$ Estonian Drug Monitoring Centre, National Institute for Health Development, Hiiu street, 11619 Tallinn, Estonia. ${ }^{5} \mathrm{NGO}$ Convictus, Syringe exchange project, Mardi. 10145 Tallinn, Estonia.

\section{Authors' contributions}

$A U, K A O, A T, K R$ and IS were responsible for and supervised the data collection in the individual studies. AU and DDJ planned the analysis for the manuscript; and MK conducted the statistical analysis. AU wrote the first draft of the manuscript. All authors contributed to revising the manuscript and have approved the final manuscript.

\section{Competing interests}

The authors declare that they have no competing interests.

Received: 19 November 2010 Accepted: 30 June 2011

Published: 30 June 2011

\section{References}

1. UNAIDS Fact sheet: 2009 [http://data.unaids.org/pub/FactSheet/2009/ 20091124_FS_eeca_en.pdf], (accessed on 03.01.2010).

2. Bridge J, Lazarus JV, Atun R: HIV epidemics and prevention responses in Asia and Eastern Europe: lessons to be learned? AIDS 2010, , Suppl 3: S86-94.

3. Mathers BM, Degenhardt L, Ali H, Wiessing L, Hickman M, Mattick RP, Myers B, Ambekar A, Strathdee SA, 2009 Reference Group to the UN on HIV and Injecting Drug use: HIV prevention, treatment, and care services for people who inject drugs: a systematic review of global, regional, and national coverage. Lancet 2010, 375(9719):1014-28.

4. World Health Organization: Effectiveness of Sterile Needle and Syringe Programming in reducing HIV/AIDS Among Injecting Drug Users. 2004. Geneva. Committee on the Prevention of HIV Infection among Injecting Drug Users in High Risk Countries. Preventing HIV infection among injecting drug users in high risk countries: an assessment of the evidence. Washington: Institute of Medicine; 2006.

5. Des Jarlais DC, Arasteh K, McKnight C, Hagan H, Perlman DC, Torian LV, Beatice S, Semaan S, Friedman SR: HIV infection during limited versus combined HIV prevention programs for IDUs in New York City: the importance of transmission behaviors. Drug Alcohol Depend 2010, 109(13):154-60.

6. Des Jarlais DC, Friedman SR, Novick DM, Sotheran JL, Thomas $P$, Yancovitz SR, Mildvan D, Weber J, Kreek MJ, Maslansky R: HIV-1 infection among intravenous drug users in Manhattan, New York City, from 1977 through 1987. JAMA 1989, 261(7):1008-12.

7. Stimson G: Reconstruction of sub-regional diffusion of HIV infection among injecting drug users in South-East Asia: Implications for prevention. AIDS 1994, 8:1630-1632.

8. Wodack A, Cooney A: Do needle syringe programs reduce HIV infection among injecting drug users: a comprehensive review of international evidence. Substance Use and Misuse 2006, 41:777-813.

9. Kivelä P, Krol A, Simola S, Vaattovaara M, Tuomola P, BrummerKorvenkontio H, Ristola M: HIV outbreak among injecting drug users in the Helsinki region: social and geographical pockets. Eur J Public Health 2007, 17(4):381-6.

10. Des Jarlais DC, Perlis T, Arasteh K, Torian LV, Beatrice S, Milliken J, Mildvan D, Yancovitz S, Friedman SR: HIV incidence among injection drug users in New York City, 1990 to 2002: use of serologic test algorithm to assess expansion of HIV prevention services. Am J Public Health 2005, 95(8):1439-44.

11. Emmanuelli J, Desenclos J: Harm reduction interventions, behaviours and associated health outcomes in France, 1996-2003. Addiction 2005, 100(11):1690-1700.

12. Santibanez SS, Garfein RS, Swartzendruber A, Purcell DW, Paxton LA, Greenberg AE: Update and overview of practical epidemiologic aspects of HIV/AIDS among injection drug users in the United States. J Urban Health 2006, 83(1):86-100. 
13. Van Den Berg C, Smit C, Van Brussel G, Coutinho R, Prins M, Amsterdam Cohort: Full participation in harm reduction programmes is associated with decreased risk for human immunodeficiency virus and hepatitis $C$ virus: evidence from the Amsterdam Cohort Studies among drug users. Addiction 2007, 102(9):1454-62.

14. Doherty MC, Garfein RS, Monterroso E, Brown D, Vlahov D: Correlates of HIV infection among young adult short-term injection drug users. AIDS 2000, 14(6):717-26.

15. Ball A, Des Jarlais DC, Stimson GV: Drug Injecting and HIV Infection (Social Aspects of AIDS) London: Routledge; 1998.

16. Vorobjov S, Uusküla A, Abel-Ollo K, Talu A, Rüütel K, Des Jarlais DC: Comparison of injecting drug users who obtain syringes from pharmacies and syringe exchange programs in Tallinn, Estonia. Harm Reduct J 2009, 6:3.

17. Uusküla A, Rajaleid K, Talu A, Abel K, Rüütel K, Hay G: Estimating injection drug use prevalence using state wide administrative data sources: Estonia, 2004. Addiction research \& theory 2007, 15(4):411-424.

18. Wilson TE, Sharma A, Zilmer K, Kalikova N, Uusküla A: The HIV prevention needs of injection drug users in Estonia. Int J STD AIDS 2007, 18(6):389-91.

19. Platt L, Bobrova N, Rhodes T, Uusküla A, Parry JV, Rüütel K, Talu A, Abel K, Rajaleid K, Judd A: High HIV prevalence among injecting drug users in Estonia: implications for understanding the risk environment. AIDS 2006, 20(16):2120-3.

20. Uusküla A, Kals M, Rajaleid K, Abel K, Talu A, Rüütel K, Platt L, Rhodes T, Dehovitz J, Des Jarlais D: High-prevalence and high-estimated incidence of HIV infection among new injecting drug users in Estonia: need for large scale prevention programs. J Public Health 2008, 30(2):119-25.

21. Talu A, Rajaleid K, Abel-Ollo K, Rüütel K, Rahu M, Rhodes T, Platt L, Bobrova N, Uusküla A: HIV infection and risk behaviour of primary fentanyl and amphetamine injectors in Tallinn, Estonia: Implications for intervention. International. Int J Drug Policy 2010, 21(1):56-63.

22. The Global Fund to Fight AIDS, Tuberculosis and Malaria, project: "Scaling up the response to HIV in Estonia".[http://portfolio.theglobalfund.org/en/ Grant/Index/EST-202-G01-H-00], (accessed on 29.06.2011).

23. Drew R, Donoghoe M, Koppel A, Laukamm-Josten U, Politi C, Rotberga S, Sarang A, Stöver H: Evaluation of fighting HIV AIDS in Estonia. WHO; 2008 [http://www.euro.who.int/_data/assets/pdf_file/0009/97794/E91264.pdf], (accessed on 29.06.2011)

24. Laisaar KT, Avi R, Dehovitz J, Uusküla A: Estonia at the Threshold of the Fourth Decade of the AIDS Era in Europe. AIDS Res Hum Retroviruses 2011.

25. Talu A, Abel-Ollo K, Vals K, Vorobjov S, Denissov G, Ahven A: 2010 NATIONAL REPORT (Based on Data from 2009) to EMCDDA from the REITOX National Drug Information Centre ESTONIA: New developments, trends and in-depth information on selected issues. National institute for health development, Tallinn; 2010.

26. Lõhmus L, Rüütel K, Abel-Ollo K, Loit HM, Talu A, Uusküla A: Prevalence of HIV and other infections and risk behaviours among injecting drug users in Tallinn and Kohtla-Järve in 2007. National Institute for Health Development/University of Tartu, Tallinn/Tartu; 2008 [http://www2.tai.ee/ TAI/SN_RDS_uurimuse_raport_2007_17.12.2008.pdf].

27. Heckathorn DD: Respondent-driven sampling: A new approach to the study of hidden populations. Social Problems 1997, 44:174-198.

28. Malekinejad M, Johnston LG, Kendall C, Kerr LR, Rifkin MR, Rutherford GW Using respondent-driven sampling methodology for HIV biological and behavioral surveillance in international settings: a systematic review. AIDS Behav 2008, 12(4 Suppl):S105-30.

29. Des Jarlais DC, Perlis TE, Stimson GV, Poznyak V, WHO Phase II Drug Injection Collaborative Study Group: Using standardized methods for research on HIV and injecting drug use in developing/transitional countries: case study from the WHO Drug Injection Study Phase II. BMC Public Health 2006, 6:54.

30. Rhodes T, Platt L, Maximova S, Koshkina E, Latishevskaya N, Hickman M, Renton A, Bobrova N, McDonald T, Parry JV: Prevalence of HIV, hepatitis C and syphilis among injecting drug users in Russia: a multi-city study. Addiction 2006, 101(2):252-66.

31. Rhodes T, Lowndes C, Judd A, Mikhailova LA, Sarang A, Rylkov A, Tichonov M, Lewis K, Ulyanova N, Alpatova T, Karavashkin V, Khutorskoy M, Hickman M, Parry JV, Renton A: Explosive spread and high prevalence of HIV infection among injecting drug users in Togliatti City, Russia. AIDS 2002, 16(13):F25-F31.
32. Connell JA, Parry JV, Mortimer PP, Duncan J: Novel assay for the detection of immunoglobulin $\mathrm{G}$ antihuman immunodeficiency virus in untreated saliva and urine. Journal of Medical Virology 1993, 41(2):159-164.

33. Parry JV, Connell JA, Reinbott P, Garcia AB, Avillez F, Mortimer PP: GACPAT HIV $1+2$ : a simple, inexpensive assay to screen for, and discriminate between, anti-HIV 1 and anti-HIV 2. Journal of Medical Virology 1995, 45(1):10-16.

34. Lakshmi V, Sudha T, Bhanurekha M, Dandona L: Evaluation of the Murex HIV Ag/Ab Combination assay when used with dried blood spots. Clin Microb Infect 2007, 13(11):1134-6.

35. Sarge-Njie R, Van Der Loeff Schim M, Ceesay S, Cubitt D, Sabally S, Corrah T, Whittle $\mathrm{H}$ : Evaluation of the dried blood spot filter paper technology and five testing strategies of HIV-1 and HIV-2 infections in West Africa. Scand $J$ Infect Dis 2006, 38(11-12):1050-6.

36. Ouwe-Missi-Oukem-Boyer ON, Hamidou AA, Sidikou F, Garba A, LouboutinCroc JP: The use of dried blood spots for HIV-antibody testing in Sahel. Bull Soc Pathol Exot 2005, 98(5):343-6.

37. Gregson S, Machekano R, Donnelly CA, Mbizvo MT, Anderson RM, Katzenstein DA: Estimating HIV incidence from age-specific prevalence data: comparison with concurrent cohort estimates in a study of male factory workers, Harare, Zimbabwe. AIDS 1998, 12(15):2049-58.

38. Wilcosky TC, Chambles LE: A comparison of direct adjustment and regression of epidemiologic measures. Journal of Chronic Disease 1985, 38:849-56.

39. Volz E, Wejnert C, Degani I, Heckathorn DD: Respondent-driven sampling analysis tool (RDSAT) Version 5.6. Ithaca, NY: Cornell University; [http:// www.respondentdrivensampling.org], (accessed 20.11.2009).

40. Platt L, Sutton AJ, Vickerman P, Koshkina E, Maximova S, Latishevskaya N, Hickman M, Bonell C, Parry J, Rhodes T: Measuring risk of HIV and HCV among injecting drug users in the Russian Federation. Eur J Public Health 2009, 19(4):428-33.

41. Niccolai LM, Toussova OV, Verevochkin SV, Barbour R, Heimer R, Kozlov AP: High HIV Prevalence, Suboptimal HIV Testing, and Low Knowledge of HIV-Positive Serostatus Among Injection Drug Users in St. Petersburg, Russia. AIDS Behav 2010, 14(4):932-41.

42. Borodin $A$, Kasemäe $R$, Klein $M$ : Narkosüüteod ja nende mõju kuritegevusele Eestis 2006-2008. Tallinn, Politseiamet; 2009.

43. WHO, UNODC, UNAIDS technical guide for countries to set targets for universal access to HIV prevention, treatment and care for injecting drug users. World Health Organization; 2009.

44. Vickerman P, Hickman M, Rhodes T, Watts C: Model projections on the required coverage of syringe distribution to prevent HIV epidemics among injecting drug users. J Acquir Immune Defic Syndr 2006, 42(3):355-61.

45. Heimer R: Community coverage and HIV prevention: assessing metrics for estimating HIV incidence through syringe exchange. Int I Drug Policy 2008, 19(Suppl 1):S65-73.

\section{Pre-publication history}

The pre-publication history for this paper can be accessed here: http://www.biomedcentral.com/1471-2458/11/517/prepub

doi:10.1186/1471-2458-11-517

Cite this article as: Uusküla et al.: Expanded syringe exchange programs and reduced HIV infection among new injection drug users in Tallinn, Estonia. BMC Public Health 2011 11:517. 